\title{
Análise da aglomeração produtiva de cerâmicas vermelhas em Campos dos Goytacazes (2011-2017)
}

Analysis of the productive agglomeration of red ceramics in Campos dos Goytacazes (2011-2017)

Análisis de la aglomeración productiva de cerámicas rojas en Campos dos Goytacazes (2011-2017)

Analyse de l'agglomération productive de céramiques rouges à Campos dos

Goytacazes (2011-2017)

\section{Rafael Carvalho da Rocha}

\section{(2) OpenEdition}

Journals

Edição electrónica

URL: http://journals.openedition.org/espacoeconomia/8930

DOI: $10.4000 /$ espacoeconomia.8930

ISSN: 2317-7837

Editora

Núcleo de Pesquisa Espaço \& Economia

Refêrencia eletrónica

Rafael Carvalho da Rocha, « Análise da aglomeração produtiva de cerâmicas vermelhas em Campos dos Goytacazes (2011-2017) », Espaço e Economia [Online], 16 | 2019, posto online no dia 30 dezembro 2019, consultado o 10 janeiro 2020. URL : http://journals.openedition.org/espacoeconomia/8930 ; DOI : 10.4000/espacoeconomia.8930

Este documento foi criado de forma automática no dia 10 janeiro 2020.

(C) NUPEE 


\section{Análise da aglomeração produtiva de cerâmicas vermelhas em Campos dos Goytacazes (2011-2017) ${ }^{1}$}

Analysis of the productive agglomeration of red ceramics in Campos dos

Goytacazes (2011-2017)

Análisis de la aglomeración productiva de cerámicas rojas en Campos dos

Goytacazes (2011-2017)

Analyse de l'agglomération productive de céramiques rouges à Campos dos

Goytacazes (2011-2017)

Rafael Carvalho da Rocha

\section{Introdução}

1 Esta pesquisa propõe um estudo e uma análise sobre a aglomeração produtiva da indústria de cerâmica vermelha em Campos dos Goytacazes. A fim de reunir elementos de apoio à nossa reflexão, tratamos das alterações econômicas, políticas, industriais e históricas do século XX que contribuíram para as mudanças nas formas de produção e organização espacial da indústria. Caravaca (1998) destaca que, neste século, houve diversas mudanças na forma de organização industrial (distrito industrial, meio inovador, cluster, meio inovador e etc.), mudanças essas que tiveram um viés político forte em alguns países (França, Itália), enquanto em outros a permanência da rigidez de certas organizações industriais culminou em uma crise que fora sentida de diferentes formas, mas em todos os países que eram considerados "grandes" industrialmente.

Harvey (2006) aponta que o mundo mudou radicalmente nas últimas décadas do século $\mathrm{XX}$, em todos os aspectos, sendo marcado por uma alteração no modelo de acumulação fordista para um modelo de acumulação flexível. o modelo fordista de acumulação implicava características de decomposição do trabalho, separação e hierarquização (verticalização) das funções, produção e consumo em massa, regulamentação do 
trabalho, sindicalização e investimentos públicos em infraestruturas econômica e social. A acumulação flexível, por sua vez, implicou uma maior flexibilidade na contratação de mão de obra (subcontratação e part-time), um aumento do poder patronal (devido a estas mudanças na contratação), uma organização mais horizontalizada dentro e fora da indústria (organização em rede) e uma redução considerável no tamanho das empresas, tornando-se, em sua maior parte, empresas pequenas e médias.

3 Este estudo tem como propósito contribuir com a análise sobre as mudanças na organização industrial, motivadas pelas modificações nos padrões de desenvolvimento desiguais, resultando na emergência desses novos espaços industriais que trazem traços desta mudança na forma de produzir, contratar e organizar-se. Na acumulação flexível, surgem novos complexos de produção localizados, tais como distritos industriais e sistema de pequenas e médias empresas, como uma sublimação do modelo da especialização flexível, pois tem como base a formação, necessariamente, de um tecido social e produtivo bastante preciso capaz de assegurar a flexibilidade

Especificamente sobre a localização empresarial (BENKO, 1999), existem certos atrativos específicos que podem fazer com que uma ou várias empresas se situem em um sítio, como, por exemplo, força de trabalho, institutos de pesquisa, atrativos da paisagem, infraestrutura de transporte e - o que ele a ponta ser o principal - serviços e clima político dos negócios locais. A abordagem espacial dentro dos estudos econômicos trouxe um fortalecimento deste cenário que contribuiu para a formação de pequenas e médias empresas, pois as sinergias coletivas fortalecem as chances de crescimento e permanência das empresas na economia local.

5 No Brasil, a designação de Arranjo Produtivo Local (APL) segue os modelos de aglomerações produtivas de pequenas empresas e sistemas produtivos territorializados, como os Distritos Industriais Italianos (BECATTINI, 1994). Trata-se de uma proposição acadêmica, amplamente usada por pesquisadores, e também política, por ter sido incorporada no estímulo ao desenvolvimento econômico territorial das localidades, combinando a reativação de economias de aglomeração com o suporte das vocações regionais. Os APL assumiram importância na agenda pública no ano de 2004, quando foram oficializados pelo governo federal como política de estímulo ao incremento da competitividade de pequenas e médias empresas. Do ponto de vista geográfico, os APL podem ser designados como concentração de empresas, principalmente de pequeno porte e com atuação no mesmo ramo econômico, que se encontram em interação entre si e com demais agentes privados e públicos.

6 O referente texto fora estruturado procurando abordar as modificações por que o capitalismo passou nos últimos anos do século $\mathrm{XX}$ e sua influência sobre as organizações territoriais, fazendo-as surgir ou extinguir unindo os fatores sociais, econômicos e históricos da região e do município de Campos dos Goytacazes, procurando uma análise fidedigna à realidade a fim de explicar o surgimento e perpetuação das aglomerações produtivas de cerâmicas.

7 Além desta introdução, o texto está estruturado em outras quatro partes, contando com as considerações finais e com as referências. Na próxima seção, discutimos as mudanças por que o modo capitalista de produção passou nas últimas décadas do século XX, enfatizando a emergências de novos espaços industriais. Em seguida, delineamos a formação socioeconômica de Campos dos Goytacazes, buscando mostrar o surgimento e 
a importância da indústria de cerâmica vermelha no município. Ao final, constam as considerações finais e as referências utilizadas.

\section{Novas dinâmicas socioterritoriais}

8 A compreensão das dinâmicas socioterritoriais exige a reflexão em torno das transformações globais e regionais de produção industrial e os principais processos que definiram o processo de produção e as cadeias produtivas. O ponto de partida é o modelo de acumulação que vinha até então regendo os processos intra e extra fabris, o fordismo. Este modelo de acumulação foi idealizado por Frederick Taylor e posto em pratica nas fábricas automotivas do Henry Ford no início do século XX. O Ford teve uma visão além da produção em massa, envolvendo mais âmbitos do que apenas a produção. Ele pensou nas horas em que o trabalhador deveria se acostumar com o trabalho contínuo, nas pausas que o trabalhador teria durante seu tempo de trabalho para aumentar a sua produtividade e, principalmente, em como e onde o trabalhador gastaria a sua renda oriunda do trabalho. Ele visualizou que havia mais fatos que influenciavam a produtividade do que apenas o incremento da tecnologia. Por isso, como bem afirma Harvey (2006), o fordismo não se restringiu apenas a mudanças na produção, senão que pressupôs a formação de um novo homem.

Harvey (2006) aponta que as empresas comportavam, internamente, o máximo possível da cadeia produtiva, ou seja, este era o modelo de acumulação em que as grandes corporações ganharam mais destaque. Os incentivos à criação dessas novas formações monopólicas e oligopólicas foram dados pelos Estados-nações propulsores do fordismo, porém contida no período pós-guerra pela crise de superprodução e superacumulação que havia se instalado anteriormente. A crença de Henry Ford no poder corporativo e no seu poder de regulação caiu por terra na crise de 1929, pois apenas o New Deal de Roosevelt conseguiu salvar o capitalismo da Grande Depressão. Esta crise fora sentida de diversas formas pelo mundo todo, inclusive pelos países periféricos, que dependiam dos Estados Unidos para escoar produção.

No auge do sistema de acumulação fordista (HARVEY, 2006), havia alto descontentamento social, pois nem todas as classes sociais foram incluídas neste sistema de produção, excluindo muitas pessoas que eram familiarizadas com trabalhos manuais tradicionais, horários mais flexíveis, ritmos menos exaustivos e controle sob o projeto do produto. Mesmo com estes fatores, a absorção de mão de obra das grandes corporações era incomparável, fazendo com que o desemprego (em certos países europeus) fosse quase nulo, o que era um fator bem favorável para fazer com que o expansionismo fordista fosse ainda mais legitimado.

11 “Assim, a introdução de equipamentos automáticos também aumentou a rigidez da produção, tornando ainda mais difícil mudar os recursos para usos alternativos" (PIORE; SABEL, 1984, p. 22). Segundo Harvey (2006), um dos motivos para as crises vivenciadas no fordismo fora a rigidez encontrada pelo excesso de incrementos tecnológicos que não se pagavam na produção. A maioria dos investimentos feitos para inovações na produção era em maquinário de alta tecnologia - que além de caros e comprados, muitas vezes, por meio de linha de crédito - não traziam o retorno lucrativo esperado; além de limitar bastante a produção, pois seria quase que obrigatória a utilização - pelo seu custo - daquele equipamento, sendo que, muitas 
vezes, o equipamento produzir especificamente um produto que já não tinha mais demanda no mercado, dificultando ainda mais o retorno financeiro.

o fato é que a rigidez do fordismo fora vivenciada de diversas formas (locacional, intrafabril, extra-fabril, relações de mercado etc.) e que muito dessa rigidez fora o próprio fordismo que criou, tornando ainda mais difícil, futuramente, encontrar onde ou como o sistema de acumulação começou a falhar. A maior parte das contradições sociais vivenciadas nessa época era promovida pelo modelo de acumulação prevalente, que promovia uma forte sindicalização, acompanhada de uma inserção exaustiva na linha de produção; promovia uma produção em massa que, muitas vezes, não tinha demanda e então não tinha o consumo em massa; promovia um forte poder corporativo onde ele, teoricamente, era independente e autorregulador, mas em que o Estado fora essencial para reduzir o que seria uma das maiores crises da história; promovia uma ideia desenvolvimentista para os países subdesenvolvidos que, na verdade, era repleta de intencionalidades ocultadas com ideais imperialistas e de ampliação de mercado para escoamento produtivo.

No final do século XX, houve uma transição de sistemas de acumulação em que o fordismo fora lentamente diminuindo a produtividade, e para que a acumulação continuasse, tivemos mudanças estruturais:

A Acumulação Flexível é marcada por um confronto direto com a rigidez fordista. Ela se apoia na flexibilidade dos processos de trabalho, dos mercados de trabalho, dos produtos e padrões de consumo. [...]. A acumulação flexível envolve rápidas mudanças dos padrões de desenvolvimento desigual, tanto entre setores como entre regiões geográficas, criando, por exemplo, um vasto movimento no emprego chamado "setor de serviços", bem como conjuntos industriais completamente novos em regiões até então subdesenvolvidas (tais como terceira Itália) (HARVEY, 2006, p. 139).

o fator geográfico definiu muitas decisões durante a prevalência do fordismo. A localização das empresas ainda levava em consideração a proximidade com a matéria prima, escoamento produtivo, proximidade com a mão de obra e o setor de serviços. $\mathrm{Na}$ atualidade, esta ideia de localização diminuiu sua importância, uma vez que, com a evolução dos sistemas de transportes, tivemos uma flexibilidade enorme nestes âmbitos da produção acima citados, facilitando bastante a forma com que a produção pode ser feita; muitas vezes, neste novo modelo, a cadeia produtiva pode ser em diferentes localidades no globo, facilitando a dinâmica da produção e se aproveitando das diferentes possibilidades que um novo espaço pode oferecer - da força de trabalho mais barata à matéria prima abundante (CARAVACA, 1998). Fatores que antes eram vistos como problemas, agora podem ser considerados solução, uma vez que uma empresa pode não se aproveitar de uma localidade no âmbito da mão de obra, mas pode aproveitar-se da matéria prima abundante.

15 A inserção dos novos espaços - feita no do período fordista no contexto do pós-guerra fora essencial também para a acumulação flexível. o fordismo inseriu estes novos espaços para que pudesse haver uma superação da crise de superacumulação criada, mas futuramente serviu precisamente para os interesses acima citados de aproveitar-se das qualidades que cada local pode oferecer. E, consequentemente, a competição espacial aumentou (HARVEY, 2006), fazendo com que muitos Estados-nações modificassem as suas políticas econômicas para receber essas empresas, visando fomentar o desenvolvimento das forças produtivas. 
16 A informação tornou-se a chave do novo modelo de acumulação. A informação não pode ser limitada a apenas um ponto de vista, portanto, no sistema financeiro, por exemplo, pode ser a chave de onde investir ou não investir, ou de saber quando retirar os investimentos feitos em determinados ativos. $O$ conhecimento pode ser a chave para uma inovação de produto que revolucionaria um determinado mercado e concentraria o lucro em certa empresa específica. 0 fato é que a informação se tornou o motor de movimentação deste novo capitalismo, pois ela, de diferentes maneiras, pode ser o mecanismo para uma nova forma de acumular capital. A esse respeito, Caravaca (1998, p. 10) afirma:

“[...] A abertura progressiva dos mercados e as novas tecnologias da informação levaram a um aumento sem precedentes de fluxos materiais e imateriais e a uma crescente interdependência entre os territórios em escala mundial além das fronteiras das respectivas nações, com a consequente perda do papel dos Estados".

17 As tecnologias da informação tiveram papel crucial na difusão das informações no novo modelo de acumulação capitalista, permitindo a criação de fluxos imateriais e materiais que conectam o mundo todo, levando a uma organização em rede que, muitas vezes, articula diferentes territórios, sobrepujando os Estados-Nações.

18 Caravaca $(1998$, p. 7) ressalta que "os processos de inovação tecnológica, reestruturação produtiva e globalização econômica, em andamento há mais de duas décadas, estão associados a importantes mudanças espaciais que definem novas formas de organização territorial". A autora cita diversas formas organizacionais (meios inovadores, regiões inteligentes, distritos industriais etc.) como sendo os principais beneficiados pelas mudanças no modelo de acumulação. Para ela, a maioria destes espaços são os que têm ligação direta com grandes áreas urbanas, por conta das facilidades que uma área urbana pode oferecer, entre elas a concentração de infraestrutura de fluidez, a presença de espaços de lazer, a mão de obra qualificada etc.

19 As áreas urbanas são aproveitadas por estas empresas pelos principais motivos: mãode-obra próxima e o "o atrativo da paisagem", que são justamente os serviços de transporte, educação e saúde que a área urbana pode oferecer. A mão-de-obra qualificada ou desqualifica, a proximidade ou não com instituições de ensino pode definir qual será o modelo organizacional que será desenvolvido nas respectivas áreas e não necessariamente será um modelo que realmente trará "desenvolvimento", uma vez que a autora Caravaca (1998) sinaliza que, para o desenvolvimento de um meioinovador (como o Vale do Silício), é necessária a existência de pré-requisitos específicos, como: criação de conhecimento, caráter estratégico de inovação, mão-deobra de alta qualificação, investigação e desenvolvimento de novas técnicas.

Para o desenvolvimento de um distrito industrial, por exemplo, não necessários outros fatore como: clima empresarial e institucional, competição e cooperação entre as empresas, economias externas de escoamento e economias internas ao distrito, trabalho manual abundante. $O$ porte reduzido das empresas proporciona uma nova organização que deixa de ser a concentração de toda a cadeia produtiva para uma só corporação, na verdade, na atualidade podemos ver que as indústrias deixam, cada vez mais, apenas o essencial na sua cadeia produtiva interna, aumentando cada vez mais as estatísticas sobre terceirização e, consequentemente, a organização em rede.

21 O sistema de pequenas empresas surge, segundo Garafoli (1978, p. 33), como uma "sublimação do modelo da especialização flexível" que, na verdade, é uma variação rápida do modelo que ele chama de especialização flexível - ou acumulação flexível, 
como é chamado por Harvey (2006) -, pois essa nova organização dinamiza a produção o suficiente para que seja criada esta nova forma de organização territorial. Ele caracteriza traços fortes desta organização como: a independência destes locais para criar uma cadeia produtiva, o "meio envolvente" ou o que Caravaca (1998) traduz como "clima empresarial ou institucional" que, na verdade, é um ambiente onde ocorrem competividade e cooperatividade em uma proporção que seja benéfica à aglomeração industrial.

22 Becattini (1981, p. 20) caracteriza o distrito industrial (ou aglomeração produtiva, termo por nós utilizado) como "uma entidade socioterritorial caracterizada pela presença ativa de uma comunidade de pessoas e de uma população de empresas num determinado espaço geográfico e histórico [...]. Onde tende-se a criar uma osmose perfeita entre a comunidade local e as empresas". Esta entidade socioterritorial, apresentada por Becattini (1981), é caracterizada por trazer uma rede de relações e escoamento local ou regional permanente.

A rotatividade de mão-de-obra é uma das principais características que a aglomeração produtiva apresenta, pois, pelas relações flexíveis, os contratantes podem adaptar a quantidade trabalho de acordo com a demanda apresentada - geralmente préestabelecida -. As trocas internas (mão-de-obra, maquinário, informações etc.) nestas aglomerações são de suma importância, pois aumentam a competividade e a produtividade das empresas. Tomar-se-á como exemplo as trocas no âmbito da mão-deobra, que estão em evidência dentro de uma aglomeração produtiva, por terem a capacidade de alterar completamente a produtividade do local.

24 Segundo Becattini (1981), a ética do trabalho e da atividade predominante do distrito faz com que cada indivíduo esteja sempre procurando uma posição que corresponda às capacidades deste trabalhador e, caso não consiga um posto de trabalho ou apresente uma produtividade baixa, ele é estigmatizado e consequentemente prejudicado futuramente. Quando um trabalhador é passado de uma empresa para outra dentro da aglomeração, a experiência anterior é reaproveitada na próxima empresa, fazendo parte deste bem comunitário que é a "atmosfera industrial” (BECATTINI, 1981). Estas informações e experiências trocadas dentro da aglomeração, de uma forma muitas vezes informal, são mais úteis que as informações conseguidas por meios formais.

Esta unidade socioterritorial apresenta uma grande dependência de escoamento fixo, sendo essa praticamente a única vinculação da aglomeração com as forças exógenas. A maior parte das relações se dá no seio do distrito e, na verdade, há um forte poder de barganha para reduzir preços de transportes, insumos entre outros objetos que podem ser utilizados internamente. As redes e fluxos internos e externos aos distritos são praticados por meio da cooperatividade - muitas vezes forçada - entre os integrantes da aglomeração produtiva que apenas buscam balancear as relações de competividade e cooperatividade para que possam chegar a bons resultados lucrativos.

Caravaca (1998) traz uma análise que põe em pauta que a presença ou não de industrialização forte em determinada zona geográfica pode fazer com que um distrito prospere ou não. No caso, a autora ressalta que, em uma zona geográfica que tenha menos indústrias desenvolvidas, um distrito industrial pode se desenvolver de uma forma mais fácil, por trazer uma espécie de segurança (por não se preocupar com competições próximas) para que um distrito possa progredir positivamente. Outro elemento que a mesma autora propõe e que é necessária, para o desenvolvimento de um distrito industrial, a especialização em torno de um produto específico, pois é mais 
fácil fazer com que as trocas internas aconteçam de forma mais fluída, por sempre ter metodologias, estatísticas etc. em comum.

A origem e o desenvolvimento do distrito industrial não resultam pois unicamente da convergência localizada [...] de certos traços socioculturais próprios de determinada comunidade [...] de características históricas e naturais particulares de uma zona geográfica [...] e de especificidades técnicas inerentes ao a determinado processo produtivo[...] são igualmente fruto de um processo de interação dinâmica entre a divisão e a integração do trabalho praticadas no distrito, a procura permanente de novos mercados para sua própria produção e constituição de uma rede de sólidas relações com os mercados externos (BECATTINI, 1981, p. 25).

As aglomerações produtivas ganharam grande relevância nos últimos tempos pela reestruturação produtiva do final do século XX, trazendo uma ideia de hegemonia deste modelo quando comparados a outros modelos territoriais. Na verdade, isso pode trazer uma conclusão errônea sobre o assunto, pois, quando é feita a análise sobre o o seu surgimento, na maioria das vezes, podemos traçar uma grande variedade de motivos, sendo eles quase sempre específicos e inerentes apenas àquela zona geográfica, fazendo com que se variem muito os motivos para a sua criação. $O$ fato é que, quando tratamos destas aglomerações, é difícil estabelecer uma generalização qualitativa, pois, quando o fazemos a respeito da criação de algum distrito, e colocamos como regra a visão de apenas um autor, provavelmente deixamos de lado algum motivo específico para o surgimento de outro distrito que não foi analisado. Por isso, fora trazido uma variedade maior de autores sobre o seu surgimento, a fim de proporcionar uma análise mais plural e integradora.

\section{Indústria de cerâmicas vermelhas em Campos dos Goytacazes}

O município de Campos dos Goytacazes, situado no norte do estado do Rio de Janeiro, é o maior em extensão territorial, sendo fundado em 1835, na época com uma economia rural e voltada para as lavouras de cana-de-açúcar e pecuária extensiva. 0 município ganhou grande notoriedade pelas atividades sucroalcooleiras que percorreram o século do século XVI ao XX, com um auge nítido no século XIX, em que a produção de sacas de açúcar duplicou, em relação ao século anterior (MORAES, 2004, p. 48).

Silva; Carvalho (2004, p. 44) destacam que, entre o final do século XVIII e meados do século XIX, Campos exibia uma extensão territorial três vezes maior do que a atual, desfrutando de localização privilegiada, recursos naturais e infraestrutura, fatores que estavam por trás de sua importância na região. É neste amplo território que era produzido o açúcar e os produtos de subsistência. A sede política era exercida pela antiga Vila de São Salvador de Campos que, no ano de 1835, assumiu a condição de cidade de Campos dos Goytacazes.

Para Bernardes; Silva (2014, p. 44-45), a região conheceu três períodos de modernização, a saber: o primeiro foi marcado introdução dos engenhos, cujo modo de produção era manufatureiro. O segundo período ocorre a partir da construção de ferrovia, em 1837, que facilitou a circulação no espaço e favoreceu o surgimento dos primeiros engenhos a vapor, no século XIX, que depois foram substituídos pelas usinas. Campos chegou a possuir 20 usinas, mas, com a perda de competitividade para a produção em São Paulo, muitas delas fecharam, permanecendo apenas duas usinas no 
município (CRUZ, 2016, p. 52). O terceiro e último período tem início no final do século $\mathrm{XX}$, com as descobertas e exploração de petróleo na região, levando a instalações de plataformas, à chegada de numerosas empresas da área petroquímica em Macaé Macaé, ao aumento dos percentuais de royalties do petróleo e participações especiais da região (PIQUET, 2004).

31 A aglomeração produtiva de cerâmica vermelha, analisada neste trabalho, teve origem no século XVIII, período em que as primeiras atividades manufatureiras de cerâmicas (telhas e tijolos) começaram a surgir no município de Campos (MOTTA; TOTTI, 2006). A aglomeração, em sua maior parte, encontra-se na RJ 216 (Rodovia Deputado Allair Ferreira) ou, como é popularmente denominada, na "baixada campista" (figura 1).

Figura 1 - Localização dos estabelecimentos de cerâmicas vermelhas no distrito de Campos dos Goytacazes.

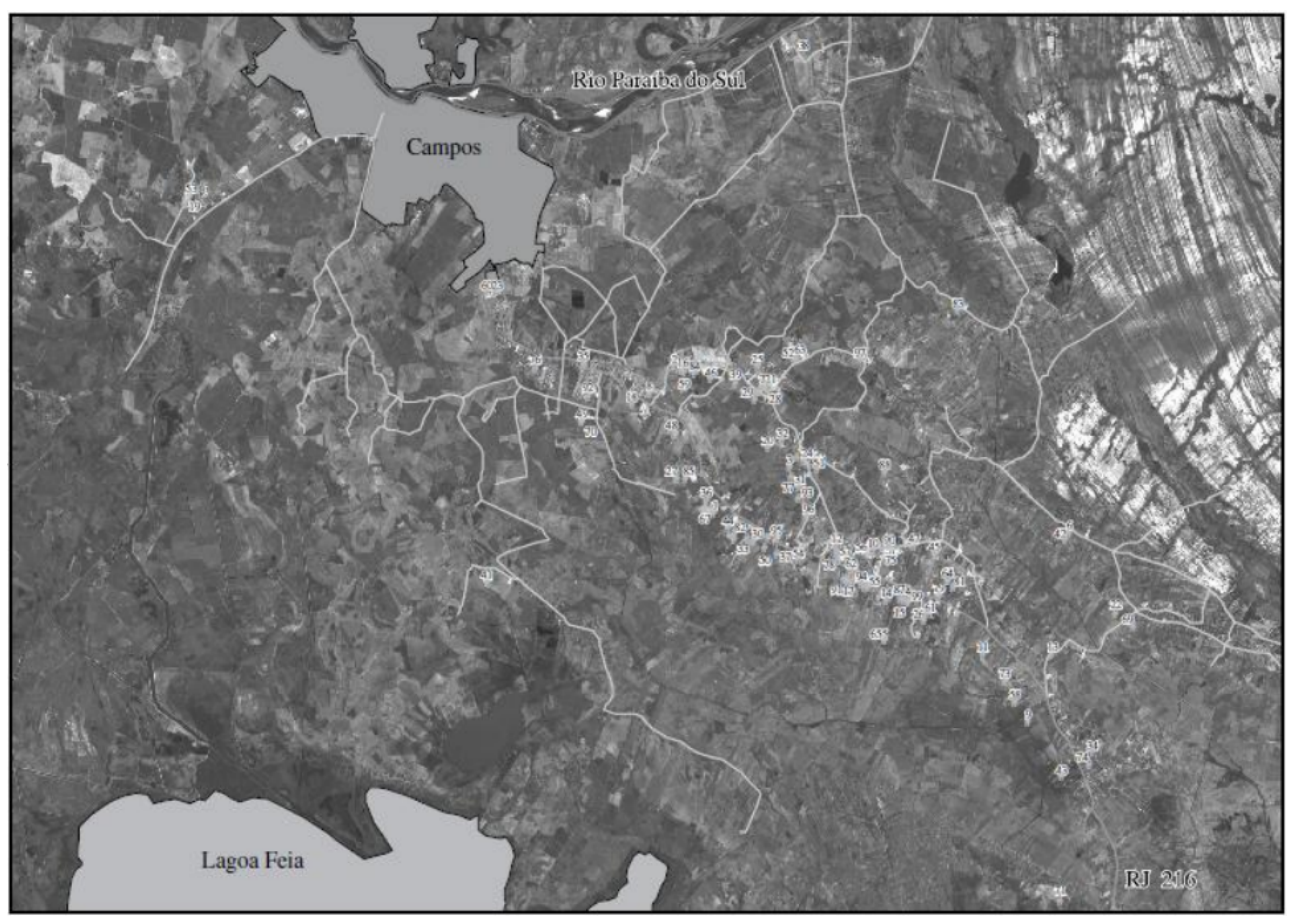

Fonte: Google maps, elaborado pelo autor

Este município apresenta indicadores sociais em que é possível notar uma evolução da dinâmica econômica e social até os anos 1980 (LA ROVERE; DE CARVALHO, 2005). Após esta década, com a crise global do capitalismo e as crises internas do país, o município vivenciou uma queda da renda per capita, um aumento exacerbado do desemprego, uma crise do setor sucroalcooleiro e uma infraestrutura básica e social que foi deixada de lado, fazendo com que município perdesse posições no ranking estadual e nacional de desenvolvimento humano.

La Rovere; Carvalho (2005, p. 75) trazem uma estatística sobre a importância dos sistemas de organização territorial de empresas de micro e pequeno porte para o município em Campos dos Goytacazes. Para eles, "as MPEs (micro e pequenas empresas) desempenham um importante papel na oferta de empregos formais, com respectivamente $27 \%$ e $26 \%$ dos postos de trabalho, ou seja, juntas elas absorvem mais de $50 \%$ do emprego formal do município". Esta unidade socioterritorial, para o 
município de Campos, tem uma importância notória por gerar uma grande quantidade de postos de trabalho:

As atividades mais importantes, no que se refere ao número de estabelecimentos, executando-se o comércio e serviços são a agropecuária (646 estabelecimentos), a construção civil (251 estabelecimentos) e a fabricação de produtos de minerais não metálicos - cerâmica (105 estabelecimentos). No que se refere ao emprego destacam-se as atividades de construção civil (3.228 empregos), agropecuária (2.553 empregos) e cerâmica (2930 empregados) (LA ROVERE; CARVALHO, 2005, p. 85).

É notória a importância da organização industrial de cerâmicas vermelhas no município de Campos, seja pela quantidade de empresas existentes, seja pela quantidade de postos de trabalhos- diretos e indiretos - gerados. O polo campista de cerâmica é o que concentra o maior número de empresas e é o de maior produtividade do Estado do Rio de Janeiro (DE SOUZA; CAVALCANTE; ARICA, 2003), podendo chegar até 1,5 milhões de peças, segundo Phiton; Brochado; Barbosa (2004), situando-se entre os maiores do país em termos de estabelecimentos e empregos. Os estabelecimentos estão limitados até o porte médio, não havendo a existência de empresas de grande porte, sendo, também, limitada a contribuição das empresas de porte médio. Segundo La Rovere; Carvalho (2005), a participação das empresas médias varia entre $0 \%$ a $13 \%$, sendo esta variação referente ao setor.

Especificamente sobre a atividade de cerâmica vermelha, as empresas de Campos formam a maior aglomeração produtiva do setor, produzindo blocos de vedação e estruturais, blocos para laje pré-moldada, tijolos e telhas (SOUZA; CAVALCANTE; ARICA, 2003; PITHON; BROCHADO; BARBOSA, 2006). Segundo Rocha et al. (2010, p. 10), “40\% das indústrias foram abertas na primeira metade do século XX e as demais foram criadas a partir dos anos 80, incentivadas pelo declínio do setor sucroalcooleiro". Parte da população acometida pelo desemprego, por conta da crise das usinas, foi incorporada pelos estabelecimentos industriais de cerâmica.

O aglomerado produtivo teve um auge no número de estabelecimentos no ano de 2012, com 133 estabelecimentos e o menor número fora de 120; o grande declínio, entre 2014 e 2015, foi marcado pela falência de sete empresas (tabela 1). Essas oscilações refletem o próprio cenário macroeconômico e a crise política nacional, em que assistimos a uma crise econômica severa, que se reflete diretamente no setor da construção civil, com diminuição do financiamento da habitação, aumento do desemprego, queda na construção de moradias etc., levando à diminuição no consumo de produtos ofertados pelas indústrias de cerâmica vermelha.

Tabela 1 - Estabelecimentos industriais de cerâmica vermelha em Campos dos Goytacazes, entre 2011 e 2017

\begin{tabular}{|l|l|l|l|l|l|l|l|}
\hline & \multicolumn{6}{|l|}{ Anos } \\
\cline { 2 - 8 } & $\mathbf{2 0 1 1}$ & $\mathbf{2 0 1 2}$ & $\mathbf{2 0 1 3}$ & $\mathbf{2 0 1 4}$ & $\mathbf{2 0 1 5}$ & $\mathbf{2 0 1 6}$ & $\mathbf{2 0 1 7}$ \\
\hline Qtde de estabelecimentos & 124 & 133 & 124 & 128 & 121 & 122 & 120 \\
\hline
\end{tabular}

FONTE: Relação Anual de Informações Sociais - RAIS, 2019

37 A estatística levada em consideração para chegar-se ao tamanho médio das empresas desta aglomeração produtiva foi o ind simples ou sociedade simples, que é uma política 
federal (LEI COMPLEMENTAR N123/06) proposta pelo Serviço Brasileiro de Apoio às Micro e Pequenas Empresas (SEBRAE). Essa política leva em consideração o tamanho das empresas, a partir do número de funcionários, para desenvolver um programa de crédito, a redução da carga de impostos e a simplificação de cálculo e recolhimento às empresas que forem consideradas micro ou pequenas. O lucro destas empresas também é levado em consideração para que possam ter o crédito liberado, o lucro deve variar entre $R \$ 360.000,00$ e $R \$ 4.800 .000,00$.

A maior parte das empresas do segmento cerâmico é classificada, pela SEBRAE, como microempresa ou empresa de pequeno porte (tabela 2), pois as suas vendas são iguais ou inferiores a 360mil reais ou iguais ou inferiores a 4 milhões e 800 mil reais, respectivamente. Quanto ao número de funcionários, para que possa ser considerada microempresa, o estabelecimento deve ter, no máximo, 19 empregados diretos. Para ser considerada uma pequena empresa, ter de 20 a 99 empregados. 0 ramo cerâmico não difere do resto dos demais ramos campistas, onde predominam empresas de micro, pequeno e médio porte.

Tabela 2 - Empresas da indústria de cerâmica vermelha cadastradas no Simples, entre 2011 e 2017

\begin{tabular}{|l|l|l|l|l|l|l|l|}
\hline \multicolumn{5}{|l|}{} & \multicolumn{5}{|l|}{ Anos } \\
\cline { 2 - 7 } & 2011 & $\mathbf{2 0 1 2}$ & $\mathbf{2 0 1 3}$ & $\mathbf{2 0 1 4}$ & $\mathbf{2 0 1 5}$ & $\mathbf{2 0 1 6}$ & $\mathbf{2 0 1 7}$ \\
\hline Não & 7 & 6 & 8 & 6 & 3 & 4 & 9 \\
\hline Sim & 124 & 133 & 124 & 128 & 121 & 118 & 111 \\
\hline
\end{tabular}

FONTE: Relação Anual de Informações Sociais - RAIS, 2019.

O mercado de trabalho campista é composto, majoritariamente, por uma mão de obra de baixa qualificação escolar, em que - por setores - o setor de construção civil e o de vestuário possuem uma escolaridade maior, mas, em sua maior parte, "mostra que $43 \%$ das empresas tem empregados que cursaram apenas o ensino fundamental" (LA ROVERE; CARVALHO, 2005, p. 86). A indústria de cerâmica vermelha não difere dessa realidade, apresentando uma mão de obra com baixa qualificação profissional e baixa escolaridade (tabela 3).

Tabela 3 - Grau de escolaridade dos trabalhadores na indústria de cerâmica vermelha

\begin{tabular}{|l|l|l|l|l|l|l|l|}
\hline \multirow{2}{*}{ Escolaridade Após 2005 } & \multicolumn{6}{|l|}{ Anos } \\
\cline { 2 - 8 } & 2011 & 2012 & 2013 & 2014 & 2015 & 2016 & 2017 \\
\hline Analfabeto & 23 & 15 & 15 & 16 & 15 & 14 & 12 \\
\hline Até o 5a incompleto & 128 & 96 & 101 & 114 & 112 & 85 & 73 \\
\hline $5^{\text {a }}$ completo fundamental & 1581 & 1401 & 1537 & 1446 & 1196 & 1072 & 1118 \\
\hline
\end{tabular}




\begin{tabular}{|l|l|l|l|l|l|l|l|}
\hline $6^{\mathrm{a}}$ a $9^{\mathrm{a}}$ fundamental & 172 & 139 & 179 & 239 & 195 & 129 & 111 \\
\hline Fundamental Completo & 632 & 717 & 764 & 764 & 746 & 651 & 600 \\
\hline Médio Incompleto & 109 & 124 & 163 & 143 & 126 & 86 & 76 \\
\hline Médio Completo & 181 & 245 & 322 & 299 & 293 & 260 & 225 \\
\hline Superior Incompleto & 1 & 0 & 2 & 4 & 4 & 1 & 1 \\
\hline Superior Completo & 7 & 11 & 12 & 10 & 8 & 7 & 8 \\
\hline Mestrado & 0 & 1 & 1 & 0 & 0 & 0 & 0 \\
\hline
\end{tabular}

FONTE: Relação Anual de Informações Sociais - RAIS, 2019 bibliografia. Atualmente, $50,3 \%$ da população empregada no segmento cerâmico é de ensino fundamental 1 completo, ou seja, uma classe trabalhadora que tem uma baixíssima escolaridade. Quando é levado em consideração o segundo grau completo, a estatística se eleva mais ainda, onde quase $90 \%(89,5 \%)$ da população empregada não têm esta formação básica de ensino. Isso é sentido de várias formas pela população, a baixa escolaridade é um reflexo do ensino público abandonado em escala nacional, e em escala local, uma população sem estudos na baixada campista; o controle patronal é mais facilitado por não ter uma mão de obra que tenha o conhecimento necessário para reivindicar por seus direitos.

41 Na verdade, essa população mal qualificada traz elementos que contradizem as teorias de formação de distritos industriais, em que a maioria delas leva em conta a mão de obra qualificada para a formação e desenvolvimento destas aglomerações territoriais, sobretudo nos países europeus.

[...] para que o conhecimento local possa gerar inovações que sejam o motor do desenvolvimento, é necessário o fortalecimento do capital social da região, entendido como conjunto de recursos individuais e coletivos que resultam de um trabalho em rede e são institucionalizados mediante o conhecimento $\mathrm{e}$ reconhecimento mútuo dos agentes envolvidos (LA ROVERE; CAVALHO, 2005, p. 80-81).

o fortalecimento do capital social da região pode vir de uma forma direta por meio do Estado, que poderia trazer políticas de revitalização das escolas públicas, modernização do ramo de produção cerâmica, qualificação da força de trabalho etc., criando condições para uma mudança no segmento cerâmico e propiciando a inovação na produção e nos produtos. Uma política setorial para esta atividade é importante, pois, como indicam Rocha et al. (2010, p. 10),

O setor de cerâmica vermelha é responsável pela alocação de aproximadamente 5.000 trabalhadores diretos e outros 25.000 indiretos, segundo o sindicado dos ceramistas de Campos. Este setor tem ainda uma importante participação na regulação do mercado de trabalho local, essencialmente no período de entressafra do setor sucroalcooleiro, empregando grande parte da mão-de-obra oriunda desta indústria.

Há uma diferença estatística quando contrastamos os dados do RAIS/CAGED (tabela 4) e aqueles apresentados pelo sindicato patronal dos ceramistas de campos. Essa 
discrepância pode ser por conta da crise econômica, que se refletiu diretamente na atividade econômica.

Tabela 4 - Empregos formais gerados pela indústria de cerâmica vermelha, entre 2011 e 2017

\begin{tabular}{|l|c|c|c|c|c|c|c|}
\hline Anos & 2011 & 2012 & 2013 & 2014 & 2015 & 2016 & 2017 \\
\hline Total de funcionários & 2834 & 2749 & 3096 & 3035 & 2695 & 2305 & 2224 \\
\hline
\end{tabular}

FONTE: Relação Anual de Informações Sociais - RAIS, 2019. (n) a proporção de mulheres é muito pequena. Em trabalho de campo na baixada campista, notamos que as mulheres se ocupam, dentro das cerâmicas, de atividades mais específicas, atuando como secretárias e vendedoras em escritórios situados próximos aos estabelecimentos industriais.

Tabela 5 - Empregos diretos, segundo o sexo, na indústria de cerâmica vermelha (2011-2017)

\begin{tabular}{|l|l|l|l|l|l|l|l|}
\hline Anos & 2011 & 2012 & 2013 & 2014 & 2015 & 2016 & 2017 \\
\hline Masculino & 2639 & 2544 & 2878 & 2797 & 2491 & 2114 & 2057 \\
\hline Feminino & 195 & 205 & 218 & 238 & 204 & 191 & 167 \\
\hline
\end{tabular}

FONTE: Relação Anual de Informações Sociais - RAIS, 2019.

A contratação de mão-de-obra na atividade industrial com pouco grau de escolarização é refletida diretamente na remuneração dos trabalhadores, pois, como pode ser observado na tabela 6 , que apresenta a quantidade de trabalhadores por faixa de renumeração, atualmente $86,7 \%$ dos empregados recebem entre 1 a 2 salários mínimos. Isso implica uma realidade bem difícil para empregados nas condições de trabalhadores das indústrias de cerâmicas vermelhas em Campos dos Goytacazes, uma vez que são enfrentadas severas e longas horas nas unidades de produção, além de fornos arcaicos - 
mesmo com a possibilidade de se introduzir fornos a gás e reduzir os danos ao trabalhador - que atingem altas temperaturas.

Tabela 6 - Trabalhadores formais da indústria de cerâmica vermelha, por faixa de remuneração média, entre 2011 e 2017

\begin{tabular}{|l|l|l|l|l|l|l|l|}
\hline Remuneração Média & 2011 & 2012 & 2013 & 2014 & 2015 & 2016 & 2017 \\
\hline Até 0,5 & 1 & 1 & 1 & 1 & 2 & 2 & 2 \\
\hline 0,51 a 1,0 & 425 & 208 & 162 & 111 & 58 & 46 & 37 \\
\hline 1,01 a 1,5 & 1634 & 1743 & 1999 & 1954 & 1700 & 1473 & 1389 \\
\hline 1,51 a 2,0 & 616 & 614 & 635 & 474 & 529 & 433 & 444 \\
\hline 2,01 a 3,0 & 83 & 95 & 185 & 370 & 274 & 221 & 228 \\
\hline 3,01 a 4,0 & 4 & 8 & 27 & 33 & 26 & 18 & 11 \\
\hline 4,01 a 5,0 & 0 & 1 & 0 & 0 & 1 & 1 & 0 \\
\hline 5,01 a 7,00 & 2 & 3 & 3 & 4 & 2 & 2 & 3 \\
\hline 7,01 a 10,0 & 0 & 0 & 0 & 0 & 1 & 0 & 0 \\
\hline 10,01 a 15,0 & 1 & 0 & 1 & 0 & 1 & 1 \\
\hline
\end{tabular}

FONTE: Relação Anual de Informações Sociais - RAIS, 2019.

A especialização produtiva interna apresentada pelo setor cerâmico é bem limitada, pois a maior parte (85\%) da cadeia produtiva, segundo La Rovere; Carvalho (2005), se concentra em atividades à montante, fazendo com que se reduza a zero as atividades de meio e fim de cadeia produtiva nesta aglomeração produtiva. A produção cerâmica na baixada campista se especializa em produção dos itens básicos para escoamento, fornecendo bens utilizados diretamente na construção civil (tijolos e telhas).

O ramo cerâmico ganha destaque em relação aos outros, pois traz uma estatística ainda que reduzida - sobre cooperações, sendo aquele que mais traz a cooperatividade entre os seus agentes, colocando em contraste as atividades da economia campista que se concentram, em sua maior parte, em situações individualistas, cada um fabricando a sua própria mercadoria e estabelecendo exclusivamente as relações concorrenciais. Essa maior cooperação tem a ver com a aglomeração de um contingente de estabelecimentos numa porção do espaço, dotado de infraestrutura viária e de concentração de força de trabalho com baixa qualificação.

A respeito dos fatores locacionais, La Rovere; Carvalho (2005, p. 106) afirmam:

A importância dos fatores locais no desempenho das empresas da configuração produtiva de campos está essencialmente ligada a fatores tradicionais como localização e infraestrutura física e de serviço, às facilidades de comunicação e transporte, à proximidade com os consumidores e ao custo da mão-de-obra. A disponibilidade de mão-de-obra e a proximidade com os fornecedores são também 
elementos de localização fortemente apreciados pela maioria dos entrevistados (LA

ROVERE; CARVALHO, 2005, p. 106).

51 Assim, essa importância de Campos na indústria de cerâmica vermelha nos cenários nacional e estadual, com mais de 100 estabelecimentos, pode ser entendida a partir de uma série de fatores. Essa atividade se expandiu no bojo da crise do setor sucroalcooleiro, especialmente a partir dos anos 1980, incorporando parcelas dos trabalhadores com pouca ou nenhuma qualificação das usinas falidas. Sua concentração na baixada campista se explica pelos depósitos próximos de argila, depositadas pelo Rio Paraíba do Sul, pela concentração de uma bacia de mercado de trabalho com baixa qualificação e amplamente disponível, pela existência de infraestrutura adequada (rodovia, equipamentos urbanos etc.), pelo mercado de bens de construção no Norte Fluminense e estados vizinhos, como Espírito Santos e Minas Gerais.

\section{Considerações finais}

52 A aglomeração produtiva de cerâmicas no município de Campos dos Goytacazes formou-se antes mesmo da tendência global de distritos industriais e de novas organizações socio territoriais, pois em torno de 40\% das cerâmicas (que é um número bem relevante) tiveram origem prévia a esta reestruturação produtiva. E, quando se fala sobre essas organizações, vale a pena ressaltar que, para a sua formação, não existe uma regra especifica e sim um conjunto de elementos que cada espaço geográfico pode apresentar, tendo em vista que, por mais que as cidades e distritos industriais do mundo sejam estandardizadas em sua forma, todas elas carregam especificidades que apenas o local pode trazer - seja esta especificidade algo cultural ou natural/físico.

53 A maior parte deste sistema de pequenas empresas perdeu notoriedade durante os anos de prevalência do fordismo, mas isso não quer dizer que estes sistemas desapareceram completamente, eles apenas perderam notoriedade global, porém, como também fora visto neste texto, até mesmo no apogeu do sistema fordista - quando a maior parte das organizações industriais era de formato corporativo e de grandes empresas -, as corporações necessitavam - de várias formas - das pequenas empresas para que pudessem se reproduzir, fazendo com que, na verdade, as pequenas empresas não desaparecessem.

54 A formação social e econômica do município de campos contribuiu para que a organização de cerâmicas pudesse se perpetuar e consolidar ao longo do tempo. A mão de obra com baixa ou nenhuma qualificação e a baixa organização sindical (mesmo durante o sistema fordista) possibilitaram que estas relações se perpetuassem da mesma forma até a atualidade, com pequenas mudanças no modo de organização e no processo produtivo, mas nada estrutural. A limitação no âmbito das inovações também pode ser atribuída a este traço do sistema territorial de pequenas empresas de cerâmicas de campos, pois a mesma forma de produzir em grandes fornos é utilizada, mesmo tendo uma grande bacia de petróleo e gás natural, que proporciona, na frente da maioria destas empresas, uma rede de gás natural. 


\section{BIBLIOGRAFIA}

ARICA, José; ELER, David; SOUZA, Sebastião. Um estudo sobre o impacto da mudança tecnológica no pólo de cerâmica vermelha do Norte Fluminense. In. Anais... XXIII Encontro Nacional de Engenharia de Produção, Minas Gerais, outubro de 2003.

BECATTINI, Giacomo. O distrito marshalliano. In: BENKO, George; LIPIETZ, Alain (Org.). As regiões ganhadoras - Distritos e redes: os novos paradigmas da geografia econômica. Oeiras: Celta Ed., 1994, 1994, p. 19-31.

BENKO, Georges; PECQUEUR, Bernard. Os recursos de territórios e os territórios de recursos. Geosul, v.16, n.32, p 31-50, jul./dez. 2001.

BENKO, Georges; LIPIETZ, Alain. As regiões ganhadoras - Distritos e redes: os novos paradigmas da geografia econômica. Oeiras: Celta Ed., 1994.

BENKO, Georges. Economia, espaço e globalização na aurora do século XXI. Editora Hucitec, São Paulo, 2002

BERNARDES, Julia Adão; SILVA, Catia Antônia. A produção social do espaço e do tempo da modernização: desafios analíticos para a compreensão do município de Campos dos Goytacazes. In. BERNARDES, Julia Adão; SILVA, Catia Antônia (Org.). Modernização e território. Entre o passado e o presente no Norte Fluminense. Rio de Janeiro: Lamparina/Capes, 2014. p. 42-56.

BOMTEMPO, Denise. Distrito Industrial. In. SPOSITO, Eliseu S. (Org.). Glossário de Geografia Humana e Econômica. São Paulo: Editora UNESP, 2017, p. 131-148.

CARAVACA, I. Los nuevos espacios ganadores y emergentes. Eure, Santiago de Chile, v. 24, n. 73, p. 5-30, Dic. 1998.

Constituição Federal: Regulamento de micro e pequenas empresas disponível em <http:// www.planalto.gov.br/CCivil_03/leis/LCP/Lcp123.htm>acessado em 22 de abril de 2019.

CRUZ, Jose Luiz Vianna da. Novas perspectivas de análise da dinâmica socioeconômica e territorial da Região Fluminense do Extrativismo Petrolífero. Cadernos do Desenvolvimento Fluminense, Rio de Janeiro, n. 09, p. 49-67, 2016.

FILHO, Edson; RIBEIRO, Alcimar. A governança em aglomeração produtiva: uma análise sobre o setor cerâmico de Campos dos Goytacazes. Revista Brasileira de Gestão e Desenvolvimento Regional, v. 7, n. 1, p. 96-129, 2011.

GAROFOLI, Gioacchino. Os sistemas de pequenas empresas. In: BENKO, George; LIPIETZ, Alain (Org.). As regiões ganhadoras - Distritos e redes: os novos paradigmas da geografia econômica. Oeiras: Celta Ed., 1994, p. $33-47$.

HARVEY, David. A condição pós-moderna: Uma pesquisa sobre as origens da mudança cultural. São Paulo: Edições Loyola, 2006.

LA ROVERE, Renata; CARVALHO, René. Campos dos Goytacazes: os desafios da transformação de um epicentro regional. In. FAURÉ, Yves-A.; HASENCLEVER, Lia (Org.). o Desenvolvimento Local no Estado do Rio de Janeiro. Estudos Avançados nas realidades municipais. Rio de Janeiro: Editora e-papers, 2005.

Legislação da SEBRAE: Lei Geral de micro e pequenas empresas disponível em $<$ http://www.sebrae.com.br/sites/PortalSebrae/artigos/entenda-as-diferencas-entre-micro 
empresa-pequena-empresa-e-mei,03f5438af1c92410VgnVCM100000b272010aRCRD> acessado em 22 de abril de 2019

MARKUSEN, Ann. Áreas de Atração de Investimentos em um espaço econômico Cambiante: Uma Tipologia de Distritos Industriais. Revista Nova Economia, v. 5, n. 2, 1995.

MORAES, Roberto; SILVA NETO, Romeu. Economia e Desenvolvimento no Norte Fluminense. Campos dos Goytacazes: WTC Editora, 2004.

PALMA, Manuel; PINHEIRO, Matheus; RODRIGUES, Kleber; ROCHA, Adriano. Inovação Tecnológica e Desempenho Empresarial: Estudo Exploratório nos Setores Maduros de Campos dos Goytacazes, RJ. Maturidade e desafios da Engenharia de Produção: competitividade das empresas, condições de trabalho, meio ambiente. In Anais... XXX Encontro Nacional de Engenharia de Produção, São Paulo, outubro de 2010.

PIORE, Michael; SABEL, Charles. The second industrial divide: Possibilities for prosperity. Basic Books Inc., New York, 1984.

PIQUET, Rosélia P. S. Norte Fluminense: mudanças e incertezas na era do petróleo. Revista de Desenvolvimento Econômico, v.6, n. 9, p. 27-35, 2004.

PITHON, Antonio; BROCHADO, Marina; BARBOSA, Claudio. Rede de Empresas: Proposta de Modelo Organizacional do Setor de Cerâmica Vermelha de Campos dos Goytacazes. In. Anais... SIMPEP XIII, São Paulo, novembro de 2006.

ROCHA, A. F.; PALMA, A. M. Gestão da Inovação e capacidade competitiva: uma análise não paramétrica no setor cerâmico de Campos dos Goytacazes, RJ. ÓRGÃO OFICIAL DA ASSOCIAÇÃO BRASILEIRA DE CERÂMICA, v. 58, 346p, abril de 2012.

TAVARES, Hermes Magalhães. Estratégias de Desenvolvimento Regional: da grande indústria ao arranjo produtivo local. Revista Brasileira de Gestão e Desenvolvimento Regional, v. 7, n.1, 2011.

\section{NOTAS}

1. Este texto é parte integrante do projeto "Economias de aglomeração e circuitos espaciais produtivos da indústria de cerâmica vermelha em Campos dos Goytacazes-RJ", financiado pelo CNPq/Pibic, sob orientação do Prof. Dr. Leandro Bruno Santos.

\section{RESUMOS}

Nas últimas décadas do século XX houve uma mudança estrutural do capitalismo que resultou na alteração no modelo de acumulação fordista para um modelo de acumulação flexível, modificando toda a organização socioterritorial e fazendo surgir novos espaços industriais. Estas mudanças atingiram o trabalho, o poder sindical e patronal e levaram ao surgimento de diferentes formas de contratação do trabalhador, fazendo com que, de modo geral, os direitos do trabalhador fossem reduzidos, deixando-os mais instáveis no mercado de trabalho. Outras mudanças vivenciadas atingiram o processo produtivo, em que a grande maioria dos 
trabalhadores, no atual modelo de acumulação, acaba tendo maior conhecimento sobre o processo de produção e maior liberdade para modificá-lo de acordo com as suas experiências e conhecimentos, tornando o processo produtivo menos verticalizado e hierarquizado e mais horizontalizado. Este texto analisa a aglomeração produtiva de cerâmica que se encontram na baixada campista (Av. Deputado Allair Ferreira (RJ-216), à luz das mudanças por que o capitalismo passou no final do século $\mathrm{XX}$, das novas organizações territoriais e do desenvolvimento econômico-social da região Norte Fluminense. Nosso objetivo principal é compreender os fatores históricos, sociais e espaciais para o surgimento e manutenção da aglomeração produtiva de cerâmica vermelha em Campos dos Goytacazes. O sistema territorial de pequenas empresas é entendido à luz de autores que abordam os assuntos de reestruturação produtiva, novos espaços socioterritoriais, sistema de pequenas empresas e distritos industriais, incluindo, também, a formação socioeconômica do município que se encontra a referente aglomeração. Os procedimentos metodológicos utilizados abrangeram levantamento bibliográfico, levantamento de dados secundários (RAIS/CAGED), sistematização e análise dos dados. Os resultados obtidos mostram que a aglomeração produtiva de cerâmica vermelha surgiu antes da emergência de novos espaços industriais, apresentando um padrão de localização concentrada relacionado à oferta de mão de obra barata e abundante, existência de argila, infraestrutura de transporte e mercado de bens da construção.

In the last decades of the twentieth century, there was a structural change of capitalism, which resulted in the change in the Fordist accumulation model to a flexible accumulation model, modifying the entire socio-territorial organization and bringing about new industrial spaces. These changes have affected labor, union and employers' power and have led to the emergence of different forms of hiring the worker, making the rights of workers generally reduced, leaving them more unstable in the labor market. Other changes experienced have reached the productive process, in which the vast majority of workers, in the current model of accumulation, end up having greater knowledge about the production process and greater freedom to modify it according to their experiences and knowledge, making the process less verticalized and hierarchical and more horizontal. This text analyzes the productive agglomeration of pottery found in the low camper (Av. Allair Ferreira, RJ-216), in the light of the changes that capitalism experienced at the end of the 20th century, new territorial organizations and economic- The territorial system of small companies is understood in the light of authors who approach the subjects of the locality of the state of São Paulo, Brazil, in order to understand the historical, social and spatial factors for the emergence and maintenance of the productive agglomeration of red ceramics in Campos dos Goytacazes. The methodological procedures used included bibliographical data collection, secondary data collection (RAIS / CAGED), data collection and analysis, and data collection and analysis, as well as the socioeconomic background of the municipality, systematization and analysis of data. The results show that the productive agglomeration of red ceramics arose before the emergence of new industrial spaces, presenting a concentrated pattern of location related to the supply of cheap and abundant labor, clay existence, transport infrastructure and market of construction goods.

En las últimas décadas del siglo XX, hubo un cambio estructural del capitalismo, que resultó en la alteración en el modelo de acumulación fordista para un modelo de acumulación flexible, modificando toda la organización socioterritorial y haciendo surgir nuevos espacios industriales. Estos cambios alcanzaron el trabajo, el poder sindical y patronal y llevaron al surgimiento de diferentes formas de contratación del trabajador, haciendo que, en general, los derechos del trabajador fueran reducidos, dejándolos más inestables en el mercado de trabajo. Otros cambios vivenciados alcanzaron el proceso productivo, en que la gran mayoría de los trabajadores, en el actual modelo de acumulación, acaba teniendo mayor conocimiento sobre el proceso de producción y mayor libertad para modificarlo de acuerdo con sus experiencias y conocimientos, 
haciendo el proceso productivo menos verticalizado y jerarquizado y más horizontalizado. Este texto analiza la aglomeración productiva de cerámica que se encuentran en la bajada campista (Av. Diputado Allair Ferreira (RJ-216), a la luz de los cambios por los que el capitalismo pasó a finales del siglo XX, de las nuevas organizaciones territoriales y del desarrollo económico- que se ha convertido en una de las principales causas de la crisis económica mundial, que se ha convertido en una de las principales causas de la crisis económica mundial. de acuerdo con la normativa vigente en el ámbito de la salud pública y de la salud pública, en el marco de la reforma agraria, sistematización y análisis de los datos. Los resultados obtenidos muestran que la aglomeración productiva de cerámica roja surgió antes de la emergencia de nuevos espacios industriales, presentando un patrón de localización concentrada relacionado con la oferta de mano de obra barata y abundante, existencia de arcilla, infraestructura de transporte y mercado de bienes de la construcción.

$\mathrm{Au}$ cours des dernières décennies du XXe siècle, il y a eu un changement structurel du capitalisme qui a entraîné le passage du modèle d'accumulation fordiste à un modèle d'accumulation flexible, changeant toute l'organisation socio-territoriale et donnant naissance à de nouveaux espaces industriels. Ces changements ont affecté le travail, le pouvoir des syndicats et des employeurs et ont conduit à l'émergence de différentes formes d'embauche de travailleurs, ce qui a généralement réduit les droits des travailleurs, les rendant plus instables sur le marché du travail. D'autres changements expérimentés dans le processus de production, dans lesquels la grande majorité des travailleurs, dans le modèle actuel d'accumulation, finit par avoir une meilleure connaissance du processus de production et une plus grande liberté de le modifier en fonction de leurs expériences et connaissances, ce qui rend le processus moins vertical et hiérarchique et plus horizontal Ce texte analyse l'agglomération productive de céramiques trouvée dans la campista de plaine (Av. Deputado Allair Ferreira (RJ-216), à la lumière des changements que le capitalisme a subis à la fin du XXe siècle, des nouvelles organisations territoriales et du développement économique). Région Fluminense du Nord Notre objectif principal est de comprendre les facteurs historiques, sociaux et spatiaux pour l'émergence et le maintien de l'agglomération productive de céramique rouge à Campos dos Goytacazes.Le système territorial des petites entreprises est compris à la lumière des auteurs qui abordent les questions. restructuration productive, nouveaux espaces socio-territoriaux, système de petites entreprises et districts industriels, y compris aussi la formation socio-économique de la municipalité qui se trouve dans l'agglomération visée. systématisation et analyse des données. Les résultats obtenus montrent que l'agglomération productive de céramiques rouges a émergé avant l'émergence de nouveaux espaces industriels, présentant un schéma de localisation concentrée liée à l'offre de main-d'œuvre bon marché et abondante, à l'existence de l'argile, des infrastructures de transport et du marché des biens de construction. .

\section{ÍNDICE}

Mots-clés: Restructuration productive, Nouveaux espaces industriels, Agglomération productive, Industrie de la céramique rouge, Campos dos Goytacazes

Palavras-chave: Reestruturação Produtiva, Novos espaços industriais, Aglomeração Produtiva, Indústria de Cerâmica Vermelha, Campos dos Goytacazes

Palabras claves: Reestructuración Productiva, Nuevos espacios Industriales, Aglomeración Productiva, Industria de Cerámica Roja, Campos dos Goytacazes.

Keywords: Productive Restructuring, New industrial spaces, Productive Agglomeration, Red Ceramic Industry, Campos dos Goytacazes 
AUTOR

RAFAEL CARVALHO DA ROCHA

Graduando em Geografia - UFF

rcrocha@id.uff.br 